\title{
1. Evaluating the impacts of pollution: an introduction and overview
}

\section{Clive L. Spash}

\section{CONTENT AND CONTEXT}

This introductory chapter sets the context within which each of the contributions falls. The aim is to show how different approaches to the management of pollution are being developed by economists while drawing out some of the common themes and problems. Economists are concerned by a wide range of pollutant impacts on the environment as they affect human welfare and not just human health, although this has formed the primary focus of regulatory authorities. The selection in this volume shows economists addressing environmental management of a variety of problems from health impacts to land contamination to ecosystems damages.

The interaction between natural science information and economic analysis can be difficult to manage as several contributors explain (Dickie, Spash, Navrud, Falconer and Hodge). In fact, varying degrees of scientific knowledge are employed in economic analyses, although all economic studies have some basis in an understanding of environmental impacts of pollutants. However, the gap between natural and social sciences, when addressing the same issue, often remains large. The studies here show how economists are grappling with the use of scientific information. One drive behind this book was to present a range of ongoing work by economists addressing environmental pollution so that natural scientists working in the areas of ecotoxicology, epidemiology and ecology might gain an understanding of typical economic practice. At the same time the volume aims to provide an opportunity for some reflection by economists as to how they use scientific information and what might be the future role of economic analyses. Thus, a range of case studies has been selected to exemplify the range of methods employed by economists as well as the type of subjects being addressed.

Economic approaches to the environment have focused upon the inclusion of monetary estimates of damages in the decision process. Questions have been raised as to the extent to which this is feasible, meaningful and politically or philosophically acceptable (Sagoff 1988; O'Neill 1993; Adams 1995; 
Foster 1997). The current volume is not directly related to this debate although the questions remain relevant and have implications for the validity of different approaches, especially in a policy context. Thus, in this chapter the opportunity is taken to reflect upon such issues as they relate to the work presented in the book. For example, three chapters directly discuss the application of monetary valuation in the area of health risks (Dickie, Dubourg and Rodríguez, Powell). However, monetary valuation in this area has also led to severe criticism. The result of putting monetary amounts on morbidity and mortality is to discriminate on the basis of the current income distribution. This means accepting that the value of a statistical life will be weighed differently due to variations in lifetime earnings, current income or living standards, and so willingness or ability to pay. Most controversially, in contributing to a cost-benefit analysis (CBA) of the enhanced greenhouse effect, Pearce et al. (1996, p. 197) claimed the value of a statistical life in India could be set at around $\$ 120000$ while in developed countries the value would be 'a best guess of $\$ 3.5$ million' and ranging up to $\$ 9$ million. The implication that human life or injuries might be treated in this way was criticized as unjust discrimination and has proved politically unacceptable. Some attempts might then be made to address 'equity' as income distribution and to do a sensitivity analysis but this is far from likely to placate the critics or address their concerns.

Part of the problem here is that mainstream economics, following the objective scientific tradition, has tried to divorce socio-economic analysis from the political and ethical dimensions of policy. Thus environmental values are regarded as objective facts to be revealed (Spash 1997). Economic analysts, who are trained at best to show some regard to income distribution issues as of secondary significance, neglect and are often surprised by their work's political reception. This has led some economists to explore a variety of alternatives such as: adopting politically set targets and then discussing whether these can be achieved at least cost (for example, Brouwer); trying to develop a range of physical impact indicators without weights and restricting analysis to the impacts of regulatory regimes for economic agents (Falconer and Hodge); and developing multiple criteria analysis and life cycle assessment of products and processes (Munda and Romo). Thus there is some divergence between economists about the extent to which monetary valuation should be applied and to which their own analysis should strive to be independent of politics and ethics.

A generally favoured alternative is to advise from the perspective of costeffectiveness to achieve given targets rather than determining targets via a full CBA. Yet, assessing costs can prove as difficult as assessing benefits and many costs of an environmental project can require non-market valuation techniques. For example, the costs of a project may involve imposing risks of morbidity or mortality. Thus, cost-effectiveness is best regarded as a 
constrained form of environmental monetary valuation and can as a result lead to exactly the same difficulties as found under a full CBA (for example, valuation of life). In reading through the contributions to this volume you will be able to reflect upon how far political and ethical dimensions can be regarded as separable from economic analysis.

The characteristics of the work presented in this volume are summarized in Table 1.1. As this shows, the case studies address different media (air, land and water) and pollutants. Air quality has formed a major concern being most easily linked to human health impacts (Dickie, Dubourg and Rodríguez). The change in Europe from local smog due to household coal combustion to the long-range transportation of pollutants from centralized electricity production has altered this relationship and the type of impacts. Acidic deposition became the first sign of this change and remains a significant factor impacting many ecosystems (Spash, Navrud, Macmillan). Awareness of the dangers of chemical wastes has encouraged a strong regulatory approach at various points in the past while economists have had relatively little to say on the matter. Thus the discussion here is of particular interest (Munda and Romo, Powell) and the idea that a purely science-based approach could be ineffective raises questions as to how socio-economic analysis can help. In contrast, the area of farming has been one where economists have played a major part in discussing production systems and regulation (for example, the Common Agricultural Policy). The view of farming is changing from merely food provision to management of a rural economy nested within environmental systems that are valued in a variety of ways (such as maintenance of ecosystems functions, and provision of habitat for rare species). Hence a move towards integrating environmental and socio-economic indicators may provide an alternative way in which to assess rural policy towards such problems as pesticide use (Falconer and Hodge).

As Table 1.1 also shows, among the commonly discussed economic methods employed for environmental CBA, the contingent valuation method (CVM), production analysis (for example, quadratic and linear programming), avoided costs and hedonic pricing (HP), are discussed and applied by contributors. In terms of the standard methods recommended by environmental economists, the production approach has been regarded as an important way of using scientific dose-response information and linking this with economics. The idea has been to use the existing results of scientific research on cause-effect relationships and plug these into existing economic models of production processes. In practice the integration requires tailoring both models and can mean commissioning new research. Due to the expense that this can imply, alternative methods of economic assessment may be sought. However, the potential is for ongoing scientific work to be conducted with an eye to economic and policy requirements without adding significantly 


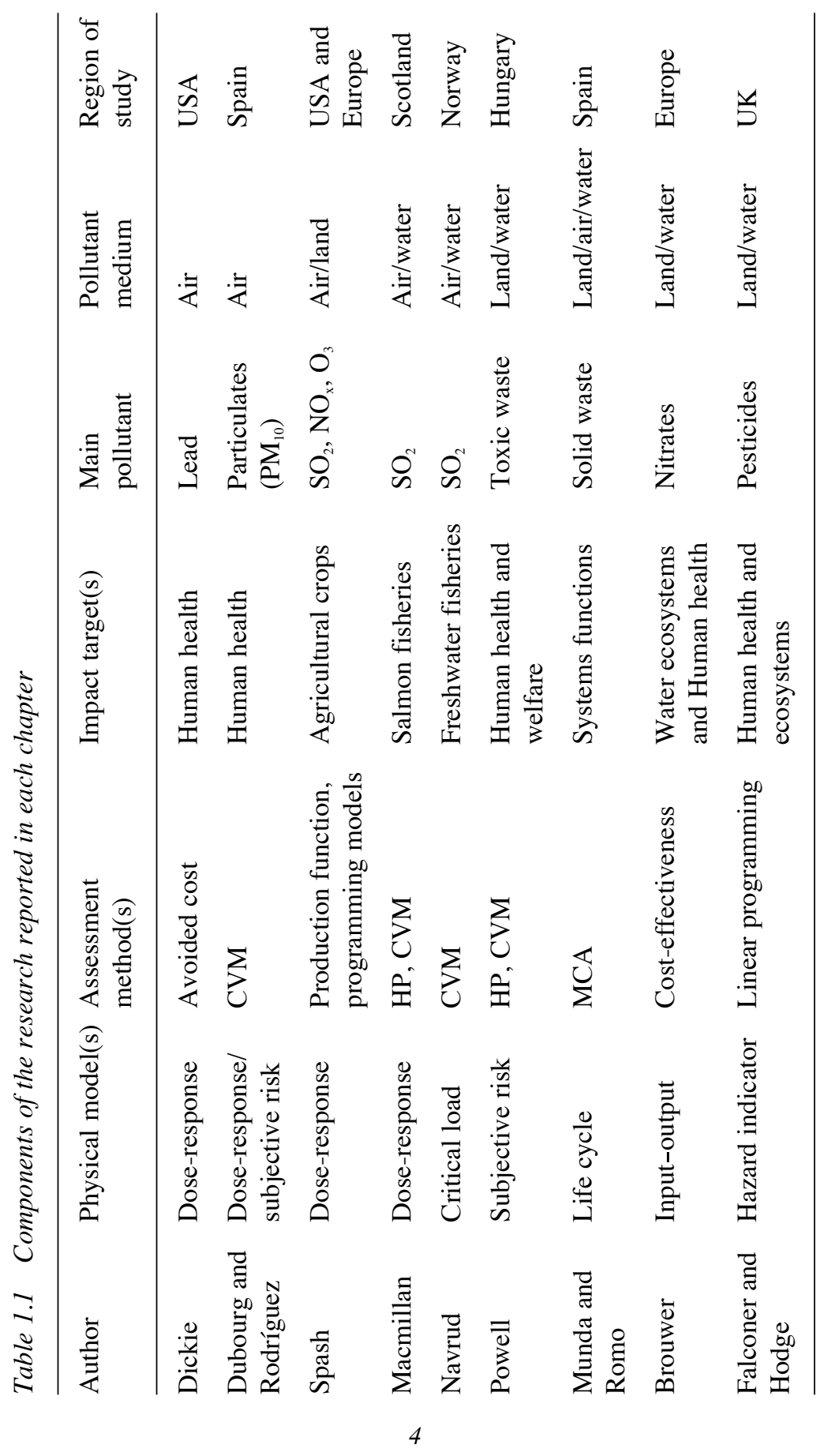


to the cost. This requires a level of communication between disciplines, which is too often absent.

Hedonic pricing appears in two of the case studies in this volume and both times in conjunction with CVM. The dual application can appear in order to validate results which might be questioned as lacking robustness if only derived on the basis of one method. The HP approach uses the value of environmental characteristics implicit in market prices such as housing, land or wages. The aim is to separate out the aspect of the environment under analysis from the overall price. For example, variations in air quality due to tropospheric ozone within an airshed can result in price differentials in houses by location. If other factors affecting house prices can be controlled for, the influence of ozone concentrations can then be isolated and evaluated. Difficulties arise in modelling all the potential factors influencing the market price (for example, for housing) and in obtaining data that allows all the factors to be measured with enough detail to conduct statistical analysis.

A currently popular method of obtaining monetary estimates, contingent valuation, is employed by several of the contributors to this volume, although this has also proved to be a controversial technique. The rise in popularity of CVM is in part due to the possibility of a potentially wide range of applications and more inclusive resulting value. In the latter regard the method attempts to assess the value associated with direct use of an environmental attribute/entity but also value associated with preserving personal potential future use (option value), with personal expectations of use by future generations (bequest value), and with personal welfare from knowing the attribute/entity exists (existence value). These last three types of value have often been incorrectly classified as 'non-use' values, but are in fact all related to an individual's personal welfare and uses or functions associated with an attribute or entity. Thus, they are more appropriately termed indirect use values, or, as in the United States, 'passive use values' (Arrow et al. 1993). As other methods are solely assessing direct use values, the potential to provide estimates of indirect use values has promoted CVM. However, despite this apparently large breadth of value categories being included within the method, there are values which fall beyond its scope and in fact beyond standard economic analysis. These are discussed further at the end of this chapter.

\section{APPROACHES FROM ENVIRONMENTAL COST-BENEFIT ANALYSIS}

\section{Primary Impacts of Pollution: Human Health}

Mark Dickie provides the opening contribution, 'Environmental toxicology and health risk assessment in the United States: economic and policy issues'. 
This chapter starts with a critical review of the natural science approach to human health impacts. As with the following chapter, the focus is upon doseresponse methods.

Dose-response function estimations via scientific experiments are seen to require extrapolation from limited data. Very high doses used on animals in the laboratory are translated to estimate the impacts of low doses on humans in the general environment. For example, chemicals may prove carcinogenic generally in rodents but have no effect on humans, leading to a false positive result. Alternatively, the laboratory tests may fail to detect any carcinogenic impact on rodents but upon release the chemical proves to be carcinogenic for humans, a false negative. Additional complications arise because humans are highly variable in response within the species, as compared to across species. Thus, a conversion factor for interspecies adjustment of dose is required and the choice of factor affects the final risk estimates substantially. The most sensitive human may be more sensitive than the most sensitive non-human.

Both quantitative (dose-response) and qualitative (hazard assessment) extrapolation are controversial. Exposure through one route may fail even qualitatively to reflect the toxicity of exposure via a different route. Other aspects of uncertainty in assessing risks from human chemical exposure arise due to multiple and cumulative exposures and the different toxicity of exposure within a population, for example, children versus adults. Toxicity assessment is an inexact science constrained further by the cost of bioassays, so that human health risks from most chemicals remain unquantified.

Government agencies must then take the available data and decide whether and how to regulate chemicals. Risk management attempts to cross the divide between science and policy, the laboratory and the world, the bioassay and economic welfare impacts of resource reallocation. In practice, Dickie argues, risk managers err on the side of caution and protecting public health and the intentional overstatement of risk is normal. The commonly portrayed dichotomy between science and policy is in fact a blurred and indistinct division.

This leads to what Dickie terms a precautionary principle where caution leads to a probable overestimation of exposure risks. In the US, for example, arbitrary factors thought to reflect uncertainty are used to make humans more sensitive than the test evidence. The population at risk from exposure is also argued to have been arbitrarily set without being related to data. For example, in the past the United States Environmental Protection Agency (US EPA) relied upon 'a fictitious "maximum exposed individual" whose unrealistically high exposures strained any appearance of scientific credibility' (Dickie).

Much discretion in regulating toxic chemicals occurs within the US because risk assessment only tries to determine whether a chemical poses an appreciable risk to a sensitive individual. Thus, some US agencies and programmes 
trade off health risks with expected benefits from chemical production while others exclude CBA and economic considerations from regulatory decisions. The regulation of lead in the US is used as a case study to illustrate the points made about the relationship between toxicology and economic assessment. Dickie argues that the economic analysis, while uncertain, does aid policy making and results in a different regulatory standard.

A central aspect of the debate discussed by Dickie is the role of science in environmental regulation. The model of scientists providing objective 'true risks' of exposure to chemicals is seen to be a fallacy. While scientific input to the decision process is essential, the role of that information must be judged in the light of the institutional structures from which it arises. Thus, scientific and economic information will be used differently in different agencies, as Dickie notes. The problem is how best to develop processes for decision making which are able to address multiple goals (safety, efficiency, equity, fairness and ethical responsibility) while avoiding capture and manipulation by vested interests.

Richard Dubourg and Maria Rodríguez, in 'Calculating morbidity benefits from reducing air pollution: a Spanish case study’, provide an example of how economics is being applied to human toxicology. This chapter considers the potential benefits of reduced human morbidity from improving air quality in the city of Vigo, north-west Spain, which suffers from acute air pollution problems. The epidemiological evidence linking air pollution with specific types of respiratory morbidity was examined. Ambient concentrations of particulate matter and ozone were related to the number of hospital admissions for pneumonia and chronic obstructive pulmonary disease (COPD), the number of visits to emergency rooms for COPD, and the number of days when activity was restricted or particular minor symptoms were experienced. This evidence was combined with the results of the first CVM survey of respiratory morbidity to be undertaken in Spain. The study tried to focus only upon the costs of 'pain and suffering' and excluded such damages as the costs of treating illness and lost wages. The authors describe how the survey was specifically designed to be compatible with existing epidemiological exposure-response functions in order to construct a 'monetized health damage function'.

More specifically, the CVM survey attempted to value the morbidity impact of pollution arising from particulate matter $\left(\mathrm{PM}_{10}\right)$ in Vigo. Primary care specialists helped the authors 'translate' various epidemiological 'endpoints' into health impacts, which were felt to be more meaningful to survey respondents. Thus respondents were presented with brief descriptions of representative 'illness episodes', which gave details of the likely symptoms, restrictions and duration of the epidemiological endpoints. These descriptions ranged from impacts associated with 'restricted activity days' to hospital 
admission due to induced illness. In accordance with the hypothetical scenario approach used in CVM, respondents to the survey were required to imagine that they experience each 'illness episode'. They were then asked to estimate their maximum willingness to pay (WTP) to prevent each episode from occurring. At the same time they were meant to focus solely upon pain and suffering and exclude their own concerns about treatment costs, lost wages or the institutional structures providing treatment. Thus, the respondent was placed in the artificial position of being asked to accept that they could avoid illness, and any treatment, by making a payment. Such an approach is commonly referred to by practitioners as the 'magic wand', because payment is assumed to remove the impacts of illness instantaneously, as if by magic.

The statistical relationship was examined between the stated WTP, the type of illness and personal characteristics of the respondents such as income and educational levels. In general, the results accorded with expectations, for example, a positive relationship between WTP and income levels. There was some evidence of an 'information effect' where those with more experience of a respiratory illness better appreciated its impacts and therefore had a higher WTP to avoid such an illness.

Mean WTP estimates were combined with dose-response coefficients from epidemiological studies. These coefficients were based upon estimates of the physical relationship between particulate matter and epidemiological endpoints, that is, epidemiological exposure-response functions. The authors then computed their monetary damage function, which linked the level of particulate matter to health costs (excluding the costs of treating illness and the loss of wages due to illness). Rather than wanting to estimate the total value of reducing $\mathrm{PM}_{10}$ levels to zero, the authors note that the costs of reducing levels by a given percentage is required for comparison with the costs of pollution control measures. They therefore estimated the economic benefit of a 10 per cent reduction in $\mathrm{PM}_{10}$ levels for Vigo.

Dubourg and Rodríguez acknowledge various difficulties with this approach. They point to factors which may cause estimates of value to be understated. For example, their study excluded the costs of treating illness, and of the increase in mortality associated with $\mathrm{PM}_{10}$. As noted by Dickie and the authors themselves, exposure-response functions ignore the fact that some groups in the population, such as elderly people and children, are more vulnerable to $\mathrm{PM}_{10}$-related illness than others. This means that the coefficients as estimated in the epidemiological studies can fail to give an accurate picture of the risk exposure actually faced by individuals. While awareness is raised as to the potential importance of such an error, the magnitude and overall direction of the error from these and similar problems remains unclear.

As with other CVM studies, the estimates of monetary damages are sensitive to analytical assumptions, such as treatment of a few large WTP bids, 
or 'outliers', and adoption of a linear monetary damage function. A very large difference was reported in the mean and median WTP to avoid all illness episodes. The median values were usually only 25-30 per cent of the mean value, indicating a few large bids at the upper end of the distribution. In effect, this implies that a few individuals are exerting a disproportionate influence on mean WTP affecting the total estimated value of pollution reduction. Such an influence is then greatly magnified when the mean is multiplied by the entire affected population. Exactly how such 'outliers' should be treated remains a matter of some controversy in CVM studies. This suggests an important role for sensitivity analysis.

Another issue related to sensitivity of the results is an implicit assumption that there is a linear relationship between the level of pollution and WTP to reduce pollution. One result is that, in this analysis, the WTP to reduce $\mathrm{PM}_{10}$ by 10 per cent is always the same regardless of whether $\mathrm{PM}_{10}$ levels are high or low. However, both the physical impact of $\mathrm{PM}_{10}$ and the perceived value of its reduction might be expected to vary, depending on the current pollution level. Sensitivity analysis might be used to identify a range of pollution levels where the findings are most relevant or, more appropriately, to test a variety of functional forms to show the sensitivity of the results.

The study illustrates the extent of effort which goes into conducting a CVM study, for example, ensuring that individuals understand the questions. Yet debate continues over many aspects of survey design. The hypothetical scenario is often criticized without thought, but scenarios should aim to be believable and realistic. Some doubts arise in this regard when considering the current state of practice in health economics CVM survey design where illness is cured instantly, if you pay. Another concern often raised with regard to the CVM is the choice of an appropriate bid elicitation method. This study employs open-ended questions although the current trend is for dichotomous choice or closed phrasing (as recommended by some expert panels). Whether such aspects of survey design should be controlled by external peer pressure regardless of practical experience, or the context of the case study, is highly questionable. For example, Willis has argued against the dichotomous choice format within the British context, while accepting it might be appropriate for the US. Thus, as with other contributions to this book, questions arise as to what is expected of economic versus natural science analysis of environmental issues and how far analysts are able to address criticisms. These are topics raised again at the end of this chapter.

\section{Secondary Impacts of Pollution}

The dose-response approach is also the subject of the chapter 'Air pollution and agricultural crop damage: can Europe learn from the United States?'. This 
attempts to draw on the more extensive experience of the US EPA in using data from the natural sciences for economic valuation studies. In particular a major research programme running for about a decade was established in the 1970s to inform US policy on the secondary impacts of pollution; this was the National Crop Loss Assessment Network (NCLAN). Primary impacts are those affecting human health as discussed by Dickie, while secondary impacts are those affecting such things as materials, crops and forests, and more generally ecosystems.

Various air pollutants have been identified as a potential influence on commercial crops including sulphur dioxide $\left(\mathrm{SO}_{2}\right)$, nitrous oxide $\left(\mathrm{NO}_{\mathrm{x}}\right)$, ozone $\left(\mathrm{O}_{3}\right)$ and carbon dioxide $\left(\mathrm{CO}_{2}\right)$. In particular, ozone in the lower atmosphere has been identified as a serious cause of crop loss in the US and seems likely to be creating similar losses in Europe. In this chapter the methods which can be applied to assess the economic damages from air pollution are critically reviewed. The methods typically require measuring pollutant concentrations, relating these to physical crop damages, and estimating the reactions of the agricultural sector and consumers to give welfare changes in terms of consumers' surplus and producers' quasi-rents. The approach taken by the European dose-response programme is shown to have neglected lessons learned by researchers in the US.

A key problem in pollutant impact assessment, which applies across economic approaches to environmental valuation, is the extent to which information can be used in different contexts. Thus, on the scientific side NCLAN faced the difficulty of using dose-response functions derived by different methods (laboratory, closed chamber, open chamber and field trials) growing various cultivars and at a variety of locations across the continent. This raised the same type of questions as are now discussed by economists in the context of transferring monetary damage estimates. Variations in experimental approach are known to influence results and thus data from one method are non-comparable with that from another. In addition, laboratory conditions are too artificial for practical application of the results, leading to the adoption of approaches which come close to field conditions but which still allow some scientific control.

One type of crop might be of interest, such as potatoes, but which cultivars are analysed will determine whether potatoes in general are regarded as resistant to given toxins. Some cultivars are resistant and others susceptible to significant damage which prevents definition of an aggregate dose-response function, but research resources mean that only a limited number of cultivars can be tested. Thus, concentration falls upon the most commonly used cultivars. In addition, varying climatic, edaphic and farm management conditions mean that the same cultivar can respond differently to the same pollutant exposure. Pollutant exposure itself is difficult 
to define and the measure chosen will affect the functional relationship derived.

Economists are therefore relying upon scientific information which is highly uncertain before they even begin to introduce their own uncertainties. On the economic assessment side there are many choices to be made affecting the derived monetary benefits from pollution control. A range of models may be chosen from simply taking the existing market price for a commodity through to conducting duality modelling. Each approach makes different implicit assumptions about how the market is operating. Even where the same approach is chosen, various choices in simulation, statistical analysis and aggregation will create great scope for diverse results. As with the scientific model the transfer of results across different regions raises another set of information transfer issues. Crop damages for farmers of potatoes in Idaho are difficult to transfer to Ontario and the consequences of doing so are unclear. Yet the pressure from agencies responsible for developing policy is to do more of this information transfer in order to avoid the costs of original research.

Overall NCLAN provides a picture of attempting a best-practice approach to dose-response estimation and the transfer of scientific data. In Europe, perhaps due to subsidiarity and a lack of a federal structure, there now exists a diverse set of dose-response results and most are non-comparable due to their design differences. In addition, emphasis has been placed upon natural science research to the exclusion of economic analysis. The demands placed upon the plant scientists by the economists under NCLAN resulted in a reorientation of the research and a focus upon the transferability of scientific functions across regions. Interestingly a similar debate about transferring information is now being conducted with regards to economic assessments.

In his contribution, 'Monetary valuation of the toxic impacts due to acidic deposition in Scotland', Douglas Macmillan is also concerned with the secondary impacts of air pollution. Although there have been a number of studies which have estimated the costs of acidification to human health, visibility, forest growth and building materials, there has been little attempt to value the benefits of abatement to semi-natural ecosystems. This partly reflects the difficulties of establishing a reliable dose-response function linking reductions in $\mathrm{SO}_{2}$ to long-term ecological change, but also the nonmarket nature of the benefits arising from environmental recovery. Macmillan has attempted to produce reliable monetary benefit estimates for recovery in the semi-natural environment of the Scottish uplands. Specific objectives were: (i) to identify impacts from acidification; (ii) to construct accurate physical dose-response functions; (iii) to link the dose-response functions to appropriate economic models in order to estimate both market and non-market benefits of recovery; and (iv) to investigate the influence of uncertainty concerning future environmental recovery following abatement. 
Macmillan employed two CBA methods. HP was used to estimate the direct benefits to anglers of reduced acidification in Galloway, while the CVM estimated the benefits in Scotland for improved biodiversity. The resulting estimate from the CVM of $£ 8-12$ billion contrasts with the $£ 4$ million from the HP study. Macmillan concludes that a narrow focus on specific user values can grossly underestimate the value of environmental improvement. This shows how a range of valuation estimates can be obtained depending upon how narrowly the environmental change or relevant population is defined and again identifies a role for sensitivity analysis.

The HP study estimated the 'direct-use benefits' to salmon anglers of reducing acidic deposition using three steps to construct a cause-effect relationship: (i) prediction of the effects of reduced acidic deposition on water quality and fish population status; (ii) linking changes in fish population status to fish catch; and (iii) prediction of the effect of higher catch on the market value of access to the salmon fishery. The latter relationship was established through estimation of an HP function. Since salmon beats are only infrequently traded in the open market, there were relatively few data from which to develop an HP model for the Galloway fishery. Instead, results were obtained from a model developed for all UK salmon fisheries by Radford et al. (1991). From the estimated relationship between the sale value of salmon beats and the average catch for each boat, a 10 per cent increase in salmon catch was estimated to create a 5.5 per cent increase in the market value of the fishery. A major assumption in this study is that the function estimated for all UK salmon fisheries was transferable to the specific case of the Galloway fishery.

The CVM study aimed to evaluate the benefits arising from an improvement in the biodiversity of polluted areas for an aggregation of indirect use and direct use values, without any breakdown. Respondents were shown pictures which were meant to convey implications for biodiversity of different levels of acidic deposition. These pictures illustrate the way in which scientific information on biodiversity is simplified for the purposes of a CVM survey. The CVM was conducted via a postal questionnaire where respondents were asked whether they would be prepared to pay a specified amount (that is, dichotomous choice). Different groups of respondents were asked whether they would be willing to pay different amounts. An 'optimal bid design method' was used to determine the number of bid amounts, the actual bidlevel values and the sample size corresponding to each bid value. The dichotomous choice approach to CVM requires a large sample size and thus Macmillan collected 1820 responses (from 3000 mailed questionnaires) while Dubourg and Rodríguez, using an open-ended question, interviewed 448 people. A logistic regression model was used to relate the probability of a 'yes' response to the bid level and other explanatory variables. Results were 
stated to be in line with expectations. From this estimation, the WTP for each scenario was estimated by integration.

Macmillan argues that omission of indirect use values would significantly underestimate the benefits of controlling the emissions which lead to acidic deposition in Europe. However, he argues that CVM is often regarded as less credible than HP since estimates of indirect use benefits are more controversial (and less tangible). While Macmillan reviews problems discussed in the literature with regard to CVM, a similar review could be made of HP. For example, Macmillan's study found problems with data availability, aggregation and the use of cross-sectional data. Other problems with HP models are outlined by Hanley and Spash (1993). In the context of this study, they include the assumption that the market value of salmon beats perfectly reflects the availability of salmon catch and that this is revised as catch levels change over time. There are also some statistical issues that can greatly affect results such as the correct functional form of the HP model. Though the problems associated with CVM are more obvious, especially to the nonspecialist, the potential for error is at least as great in an HP study. This raises the question as to the extent to which the results from different valuation methods should be used in policy analysis.

The policy problem of acidic deposition is also the concern of Ståle Navrud in 'Linking physical and economic indicators of environmental damages: acidic deposition in Norway'. This chapter provides an exploration of the uses being made of natural science versus economic information. Navrud argues that there are two distinct ways of introducing the sustainability concept in decision making, either as an exogenous variable in the form of physical indicators or as an endogenous variable in economic models, that is, economic indicators. These two approaches are termed here 'strong sustainability' and 'weak sustainability', respectively. This chapter is an attempt to provide links between these two concepts, by using the indicator of critical loads to describe the environmental change to be valued in a CVM survey. The goal was to integrate strong sustainability concerns with the damage function approach of environmental economics. The case study presents results on the willingness to pay of the Norwegian population for increased freshwater fish stocks which result from reducing exceedance of critical loads for sulphur.

A similar approach to that of Macmillan is employed using four main steps. First, air dispersion models are used to estimate how changes in pollution emissions affect atmospheric concentrations. Second, calculations are made as to how changes in atmospheric concentrations of pollutants affect acidic deposition and concentrations at the target (soil, water). Third, dose-response functions are used to calculate the impacts on affected ecosystems (for example, fish stocks). Fourth, economic damages are estimated using CVM. 
The second and third steps consist of calculating changes in critical load exceedance and its impact on fish stocks.

In-person interviews of 1009 Norwegian households was carried out using both open-ended and dichotomous choice formats. Many respondents stated zero WTP because they thought that the countries causing the depositions should pay, rather than because they had no utility from increased fish stocks. Treatment of these protest zero bids then created a problem for the analysis, but as Navrud notes: 'this type of protest behaviour is found in most CV studies'. Results from the two formats were used to give a range estimates of the WTP.

Next, Navrud discusses the use of benefit transfer techniques to calculate European welfare gains from reducing acidic deposition. There are two main approaches. First the unit value at the study site (Norway) is assumed to be representative for the policy site (Europe) either with or without adjustment for differences in income levels. Second, a benefit function is either estimated at the study site and transferred to the policy site, or estimated from several study sites using meta-analysis. Once a function is available then values for variables at the policy site can be obtained to estimate WTP. Navrud concludes that reliable estimates for CBA could be obtained from a benefit function approach. However, some assumption would be required to use the results of the current work including that the marginal WTP is constant, that is, independent of the current level of acid deposition, and that Norwegians are representative of all Europeans with regards to WTP for reducing fish damages.

\section{Primary and Secondary Impact Assessment}

In 'Prioritizing toxic chemical clean-up in Hungary using monetary valuation', John Powell also refers to benefit transfer, but he is primarily concerned with providing economic information to improve the approach being taken to regulate pollution. Estimates of the number of contaminated sites in Hungary vary widely from 3000 to 12000 and the Ministry of the Environment has reasonable levels of information on only 175 'priority' sites. Estimated cleanup costs for even the two-thirds of these sites on a priority list far exceed the budget of the decontamination programme established in 1996. One site alone has an estimated clean-up cost of $£ 10$ million while the annual budget is only $£ 3$ million. Decontamination of sites must therefore be prioritized. This chapter examines the potential for estimating the social and environmental benefits from removing health risks and environmental impacts, derived using market and non-market valuation techniques, in order to rank contaminated sites. Quality and quantity of information required are both issues that need careful consideration in a transition economy where financial resources, 
scientific and economic information, and environmental expertise are low. The study investigates the extent to which limited economic valuation information can improve the decision over the removal of toxic waste.

An initial issue which arises and tends to be at best implicit in economic valuation work is the institutional context. There are problems with trying to decide upon decontamination of land where ownership is uncertain and priorities for resource use in this area are low. However, contamination is more than a historical problem of past lack of responsibility because new sites are being created, partially due to the pressure for industrial and material growth. Economists are familiar with the incentives created by the free market system for private firms and individuals to externalize any costs possible, including environmental costs. Thus, government intervention is necessary, but how this should be guided remains unclear. A purely natural science approach to assessing the risks seems inadequate because risk is largely associated with human impacts which must then relate to socio-economic indicators.

In fact, Powell argues that a natural science risk assessment procedure is flawed and that an explicit acknowledgement of socio-economic factors is required. He uses a case study to suggest how this might be achieved. However, the reliance on purely monetary estimates of individual preferences about contaminated sites, which he employs, can also be viewed as inadequate. Once wider concerns of socio-economic values are touched upon the incommensurability of economic, social and ethical values arises. This problem applies equally to all monetary valuation methods such as the property value approach or CVM, both of which Powell employs. All such methods are also dependent on individual knowledge and perception of environmental hazards, and public understanding of toxicity. Thus a range of issues are relevant to risk management involving expert versus public opinion. This is where economists conducting CVM studies are found discussing the provision of information and how to inform an often ignorant general public about complex environmental problems in relatively short surveys. The alternative of relying upon scientific experts seems equally problematic and undemocratic.

While Powell shows how benefits may be relatively large, the question of whether individual preferences reflected via monetary payments are a good approach to ecotoxicology is not addressed. The recommendation is again made for using benefit transfer. The reasoning is that enforcement agencies can save money by avoiding original research. However, there is no reason to believe a priori that public preferences about one toxic waste dump should match those of a different public about a different site. Thus, the issues raised by earlier chapters seem to confront the analyst in Eastern Europe even more explicitly. 


\section{Alternative Assessment Methods}

In 'Combining life cycle assessment and multicriteria evaluation: comparing waste management options in Spain', Giuseppe Munda and Marta Romo move away from the standard approach to pollution evaluation taken by economists. Using the example of waste management systems in northern Spain, they compare different systems with energy recovery, including several subsystems like transport, plant management and electricity production. The chapter addresses a theoretical and empirical analysis of different waste management alternatives. The theoretical issue tackled is the use of a multicriteria evaluation approach in combination with a life cycle assessment framework because the two approaches are thought to be complementary and mutually reinforcing. Life cycle assessments generate indicators of potential impacts on the environment and humans. In the life cycle assessment, the following impact categories were considered: toxicity for humans, greenhouse gas releases, eutrophication, acidic deposition, ozone layer depletion, smog, energy consumption and solid waste generation. Multicriteria methods can be used to aggregate such indicators in order to arrive at a final evaluation. The promise of multicriteria is to avoid reduction of indicators to a common unit of measurement, as normally practised by environmental economists using money.

This chapter contrasts with the approach suggested by Powell. Multicriteria analysis (MCA) is recommended with detailed analysis of life cycle implications of waste management systems. The chapter gives technical details as to the conduct and performance of the approach and some of the possibilities this holds. An interesting aspect of this type of MCA is the potential to explicitly address distributional criteria and maintain several non-equivalent measures of performance through to the final report. As in the case of reporting sensitivity analysis, the outcome is then seen within a broader context and the hope is that results will be used as a package rather than single numbers being plucked for use out of context.

The final two contributions relate economic analysis of environmental pollution to the policies which might be employed for controlling that pollution. Brouwer takes a broader view than some of the other studies in the book and reflects upon his experience in 'Cost-effectiveness analysis for nitrate pollution control in the European Union'. Nitrate pollution is a problem heavily related to farm practices, that is, the use of nitrogen fertilizers and intensive animal farming. He considers cost-effectiveness of pollution control at two levels. First is the relative cost-effectiveness of different taxation policies. Second, he considers a cost-effective response from a farmer's point of view. These issues are especially relevant in the context of various 
European Union directives that are expected to reduce nitrate pollution in all member states.

Differences in the physical nature of the nitrate problem across Europe are reviewed before discussing the cost-effectiveness of different regulatory approaches. In particular, product taxes are compared with farm-level taxes on nitrogen surpluses. Although Kleinhanss et al. (1997) provide evidence for considerable reductions in fertilizer use if a levy reaches 50 per cent, the policy would only have a very limited impact within 'hot spot' areas where producers often engage in intensive livestock production. In contrast, Helming (1997) shows that a tax on nitrogen surpluses at the farm level is much more cost-effective than a product charge. This emphasizes the importance of the regional distribution of pollution when considering policies at a national or international level.

At the individual farm (or firm) level, when regulations are introduced on nitrate leaching, farmers can respond either by altering the intensity of production or by changing farm management techniques. Brouwer reviews the merits of the different options open to farmers and outlines the different ways economists look at this question. For example, one option is simply to compare farms following 'sustainable management practices' with a control group. A more formal economic approach, such as that used by Schleef (1996), is to use a linear programming model to consider the costeffectiveness of different options open to farmers. Options considered by Schleef include transportation of animal waste, renting land, and changing the feed diet of livestock. Brouwer's general conclusion is that farmers often have management options which allow for a more cost-effective way to reduce nitrate pollution than by reducing livestock numbers, but this is neglected when devising policy.

Falconer and Hodge, in 'Pesticide policy design and decision-making in the United Kingdom: information, indicators and incentives', discuss issues relating to both the chapter by Brouwer and that of Munda and Romo. That is, they are concerned with both the pollution impacts of farming and its regulation, but also the use of indicators in economic assessment and for policy guidance. They focus upon the construction and role of indicators in environmental policy using the example of agricultural pesticide regulation. This has become particularly relevant in European countries following the implementation of the 1980 European Drinking Water Directive. In addition, the Fifth European Union Environmental Action Programme proposed a reduction in the use of plant protection products as a major objective for the agricultural sector. Falconer and Hodge show how the use of environmental indicators can contribute to the identification of cost-effective policy options to reduce the overall use of pesticides.

The chapter begins with a discussion on the nature of the pesticide problem, 
before explaining the role and then the construction of environmental indicators. Generally, environmental indicators synthesize information collected by other types of impact assessment methodologies. They are then seen as potentially fulfilling several roles as decision aids which include: providing a simple framework within which to start assessing the social and environmental impacts of damage, allowing clear identification of the relative hazards of different products (for example, by pesticide users), and providing a basis on which to differentiate regulatory regimes for diverse products.

Issues in the construction of indicators are explored at a general level and via the case of pesticides. The general discussion includes data availability and assumptions, impact variability in time and space, aggregation and weighting of components and how to incorporate economic information. Weighting of different aspects of environmental damage in constructing an environmental indicator raises the question as to what extent the results from economic valuation studies can be employed. The pesticide indicator in the case study involves ranking a selection of the most commonly used arable pesticides on the basis of their potential impact on the environment. The simple summation of very different components (from hazards to bees through to human health) further emphasizes the weighting problem.

Finally, Falconer and Hodge use their case study to examine the correlation between the volume of pesticide use, financial costs of farm production inputs and ecological hazards. They show that the impact of a pesticide tax may differ greatly depending on whether it is linked to spray costs (for example, if it is implemented on an ad valorem basis), or to quantities such as the number of units used, or differentiated according to the adverse environmental potential of the product.

\section{ISSUES IN CURRENT ECONOMIC ASSESSMENT OF POLLUTION}

Several different aspects of the way in which economists are trying to address pollution problems can be identified among the various case studies. Most prominent appear to be the validity of results and methods, the use of information, and sensitivity analysis. In addition, the work presented in this volume requires some qualification in terms of what is expected from economic valuation. Thus, this section returns to the issue, mentioned earlier in the chapter, of the theoretical limits to economic valuation.

\section{Convergent and Conduct Validity}

One approach to validating the results from economic or scientific studies is 
to repeat the work. This can be done under identical conditions to see if results can be repeated or under controlled variations to identify the variety of conditions which affect results. The strict approach requires controlling for all unwanted influences so clear cause-effect relationships can be identified. This is rarely possible in scientific fieldwork or socio-economic studies.

In economic valuation work the results from using two different methods is sometimes compared, for example HP and CVM, in order to test convergent validity. Convergent validity concerns the extent to which different methods for valuing a given environmental change produce similar results. Thus, if an HP study gives a similar result to a CVM study, the analysis is regarded as converging on a single answer. This can raise several difficulties because the implementation of any one method requires several choices affecting the resulting monetary estimates. Sampling, data analysis and survey designs all introduce possible bias and errors into the monetary estimates. Controversy surrounds whether open-ended formats (Dubourg and Rodríguez) or dichotomous choice formats (Macmillan) should be used in asking bid questions, and over the use of WTP versus willingness to accept (WTA). Convergent validity studies often seek to define acceptable bounds within which estimates should fall and also common terms and conditions which studies should meet. Thus, Cummings et al. (1986) defined a set of 'reference operating conditions' and used plus or minus 50 per cent overlap in estimates of consumers' surplus as signifying convergence.

More recently, the National Oceanic and Atmospheric Administration (NOAA) commissioned a panel (including Nobel prize winning economists Arrow and Solow) to judge whether CVM was a valid technique for measuring passive use values associated with natural resource damage assessment. The resulting report both endorsed the method and set down a series of recommendations for conducting a CVM survey which were meant to be definitive (Arrow et al. 1993). However, a volume of studies critical of CVM and many of the recommendations of the NOAA panel was also produced at the same time (Hausman 1993). The NOAA guidelines assumed survey redesign could avoid all the problems and questions raised by CVM research over the preceding 20 years.

The NOAA report has been criticized for failing to consider all the relevant arguments and for being limited to a specifically American context. For example, one key recommendation was to use a referendum (dichotomous choice) format where the respondent is asked whether they would pay $\$ \mathrm{X}$ and must answer 'yes' or 'no'. As Willis (1995, p. 127) has pointed out:

The NOAA Report failed to consider in detail arguments against the use of referendum formats. There is no definitive evidence that referendum models outperform open-ended (OE), payment card (PC), and iterative bidding (IB) formats for public goods. There is simply no 24-carat gold standard against which results 
from different methods can be compared. Further, people in Britain are unfamiliar with voting on tax propositions, compared with people in the USA...

As an experienced CVM practitioner, Willis concluded against the exclusive adoption of referendum formats in Britain. There are other areas where the NOAA recommendations are unsatisfactory and open to question. For example, some of the difficulties facing a CVM practitioner are the extent to which budget constraints and substitute goods should be stressed; how framing, choice of bid vehicle and elicitation method can be decided when opposing parties have an interest in the analysis; and when an adequate amount of information has been provided. Also, among their controversial recommendations was the blanket use of WTP, despite noting that WTA is theoretically required for damage assessment. As Knetsch (1994) has noted, the NOAA panel argument that 'conservative values' are in some sense to be preferred and will be forthcoming under WTP formats is a poor defence and the results are likely to 'compromise the valuations and seriously distort incentives' (p. 356).

More generally, while the NOAA guidelines did include some sensible suggestions for survey conduct (many recognized good practice) they also neglected a series of questions raised by psychologists, among others. These research issues include: mapping CVM responses in relation to factors such as equity and ethical considerations in order to understand contingent perceptions of the environment; understanding the processes by which people arrive at their stated intentions to pay or accept payments; and the effect of information provision (Willis 1995). This implies neglect of the social construction of preferences. As Vatn and Bromley (1994, p. 132) note: 'Societal processes form the context within which individual preferences are both developed and supported. Valuing that fails to recognise the pre-eminent role of context in preference formation will fail to produce coherent valuation estimates'.

\section{The Role of Information}

\section{Information provision and environmental education}

Information is discussed in environmental valuation work in two broad contexts. First is the concern over the level of ignorance among members of the general public about environmental issues and in particular those they are being asked to value. Second is the interaction between scientific and economic information and the extent to which information can be used out of its original context. This applies both to economists using scientific information and to policy makers using the results of one study at another time and location.

The limited extent of public knowledge over the environment is of obvious 
concern if they are to make judgements informing policy on the basis of their preferences (as assumed in CBA). In revealed preference studies, individuals are assumed to be well informed about the environmental issues of concern. For example, there would be no reason to expect that air pollution would influence house prices if the general public were unaware of the pollution problem in the first place. The information issue has become controversial with the use of CVM because the analyst must decide the extent, type and format of information respondents should be given about the environmental entity to be valued. This problem is exacerbated when an environmental change being valued is something about which respondents are generally unaware, for example, as shown for understanding of biodiversity degradation in the UK even among highly educated groups (Spash and Hanley 1995). In such cases the valuation process becomes an educational process and forms the view of respondents, perhaps dramatically changing their perception of an issue. If CVM is a process of providing information which changes preferences, then the sample results cannot be extrapolated because they are no longer representative of the general population.

One reaction to this kind of problem is to argue in favour of deliberative processes for valuation. These may be seen as supplementing existing methods such as CVM (Brouwer et al. 1999). Alternatively, the point of the monetary valuation exercise may be diminished by the deliberative process and seem a rather technical abstraction from the pluralism of discussion. Thus, the argument has been made in favour of accepting that some choices can be made without monetary pricing (Vatn and Bromley 1994; O’Neill 1997). This encourages a wider discussion of deliberative institutions for value articulation.

\section{Information and benefit transfer}

An aspect now being developed which some authors (Powell, Navrud) raise is the scope for benefit transfers. The attraction of benefit transfer is the potential to reduce costs. If, for example, the mean WTP, or a benefit function, estimated in one location were transferable to another location, this would avoid the need for more original research. However, a robust transfer technique might result in sizeable costs of its own in order to check for the validity of making such a transfer in the first place.

There are various methods for testing the benefit transfer approach. The general principle is that site-specific benefit estimates based on a particular method (such as HP, CVM) are compared with the estimates which would result from function or mean value transfer from another site. As Bergstrom and DeCivita (1999) point out, there are several potential sources of error due to differences in context between sites. Hence site valuation will be influenced by the specification and measurement of environmental changes and the 
availability of substitutes and complements with respect to site attributes. According to Brouwer and Spanninks (1999), significant influences on individual preferences should be accounted for by the benefit function and be of similar magnitude across sites. These are regarded as necessary conditions for the validity of benefit function transfer. The essential concern is for comparability across site characteristic such as: the type of users, the quality and quantity of environmental changes. In addition, the quality of the studies which produced the original functions or estimates must be questioned.

The approach is used in the US to supplement CBA (Bergstrom and DeCivita 1999). The general principle is also more commonly practised than many realize because economists typically borrow scientific information from other contexts even when conducting original economic valuation work, as shown in the chapters of this volume. In addition, existing numbers are often used out of context in policy circles. This is of concern because there are numerous potential problems which can make such transfers of information, whether dose response or economic, questionable (Spash). However, very little published evidence exists concerning the validity of transferring point estimates of the monetary value of environmental benefits or complete benefit functions from one site to another (Brouwer and Spanninks 1999). The research which has attempted to evaluate the performance of benefit transfer suggests that this practice can lead to serious errors in estimation (Downing and Ozuna 1996; Kirchhoff et al. 1997). Thus the validity of benefit transfer remains highly controversial.

Although existing research implies that the welfare measures produced by benefit transfer are inaccurate, compared to original case-specific research, the degree of accuracy has been regarded as adequate by Bergstrom and DeCivita for helping set broad policy priorities. However, where decisions threaten to produce irreversible losses of rare environmental attributes, a primary study is deemed preferable. Hence, in the chapter by Macmillan, where an HP function was transferred, the result would then be regarded as providing an order of magnitude for the benefits to anglers of reducing pollution by acidic deposition. Indeed, in the light of the many other problems with valuation methods, any welfare measure will be only a crude estimate of the value of an environmental change (or some components of that change). This has led some economists to look towards specific forms of multiple criteria analysis as a potentially more informative approach where original information can be preserved (Munda and Romo).

\section{Sensitivity Analysis}

While many analysts agree that conducting data runs to show how sensitive results are to changing specific variables is a good idea, very few actually 
present such data. As Merrifield (1997) notes, the coverage given to the topic in CBA texts is limited and the topic is more often ignored altogether. Yet sensitivity analysis could provide a considerable amount of information concerning the robustness of results.

As was mentioned earlier, for example, the treatment of outliers in CVM studies can have a large influence on aggregated WTP values. More generally, CVM practice is inconsistent with regard to how different motives to bid are treated in data analysis. Thus some zero bids are regarded as 'protest bids' and excluded from data sets while motivational questions are absent from screening of positive bids (such as outliers). This creates considerable potential for variation in results from the same data set. There appears to be a neglected role for sensitivity analysis in such work. Thus, mean WTP, preferred as a basis for welfare estimates, should be compared with a median WTP estimate. This might also enhance the credibility of such studies.

More generally, results can be difficult to interpret because single numbers are given after a poorly described aggregation process. Results can be highly sensitive to factors such as population size and discount rates. For example, a recent report from the UK Department of Environment, Transport and the Regions (1999) used a 25 per cent discount rate in aggregating the results of a CVM study. This is extremely high compared to any CBA or public policy appraisal process but there was no sensitivity analysis on this factor in the report. The only comment in this regard was a footnote which mentions a 5 per cent change in discount rate causing a 10 per cent reduction in WTP. Thus, if the relationship were linear, something in the order of a 40 per cent reduction in WTP was made to the final results over the more normal 6 per cent discount rate used in UK public policy appraisals. The study employed a panel of experts (Ian Bateman, Nick Hanley, Michael Hanemann, Susana Mourato, Richard Ready and Ken Willis) and 'an approach that is more likely to produce conservative results' (p. 12). This was the largest CVM study ever conducted in the UK (with a sample of 10640 public interviews) and was used to inform a decision by the Treasury as to whether they should implement a tax on aggregates extraction (which has not yet happened). A policy maker reading the executive summary would never come across the sensitivity of the results to the discount rate or other factors.

There is some risk of both unintended and deliberate data manipulation in the complex calculations, often implicit, in a benefit assessment exercise. Merrifield (1997) argues that sensitivity analysis can make a CBA more informative, can discourage abuse and make inadvertent bias more transparent. He also believes that it would help prevent the practice among public officials of ignoring those CBA results which are unpalatable to special interest groups. The outcome would also move studies away from concentration upon single numbers and lead to the provision of data within 
ranges, although single numbers might still be defended within this context. The drawback for the policy process is that the complexity of environmental valuation would no longer be something which might be relegated to an annex of a report. As Merrifield (p. 91) notes, each additional factor added to a sensitivity analysis at least triples the number of tables reporting net present values. However, if the outcome was far greater transparency in the conduct of CBA, and public policy, then this could be a small price to pay. Either way, the current practice of doing little or no sensitivity analysis and relegating decisions over key factors to footnotes seems unjustifiable.

\section{Limitations to Economic Valuation}

A category of values can be recognized which are by definition outside of the economic calculus to evaluate. The category is mentioned here in order to qualify the discussion over the extent to which economic techniques can achieve a comprehensive valuation of the costs and benefits of environmental pollution. Non-economic values can be related to notions of intrinsic value outside of good for human ends, and non-consequentialist and non-utilitarian reasoning about the environment. For example, a species may be valued as a food source and because it is beautiful and because of its potential to benefit science, but it may also be valued separately from all these uses or aspects of its nature which create good consequences for humans. Economists employ an ethical theory (teleology) which places the ultimate criterion of morality in some non-moral value (for example, welfare, utility and happiness) that results from acts. This theory then judges acts as only having value if they lead to good consequences (instrumental value), and sees the only intrinsic value as being in the consequences of these acts. In contrast, alternative ethical theories (for example, deontology) attribute intrinsic value to features of the act themselves. For example, killing a human is wrong even when the outcome is judged to be better. The act is judged on its own rather than by the outcome. Such values are exemplified by concerns for justice, human rights, the rights of animals and religious convictions.

One aspect of this alternative approach to valuing the world around us is that some things are not for trade, sale or exchange. The refusal to trade can be particularly relevant when environmental degradation affects human health, animal welfare and ecosystems' functioning and structure. In these cases intrinsic values in non-human animals, plants or ecosystems may be recognized by individuals as constraining economic trade-offs. Studies show a substantial minority of respondents to CVM surveys for biodiversity and wildlife claim rights-based beliefs (Spash 1998, 2000). The extent to which such preferences are liable to arise in other contexts, or be applicable to other economic valuation methods, is unclear. However, excluding such 
respondents to a CVM as protest bidders, because their behaviour diverges from the accepted economic model, seems at least unscientific.

The discussion of intrinsic values has been rather limited in environmental economics. The idea has been expressed that existence values in CVM might capture non-utilitarian values and are a sign of concern for non-human intrinsic values or rights (Pearce et al. 1989; Pearce and Turner 1990). However, while an individual's WTP for such things as species preservation, or biodiversity, may be showing respect for non-human intrinsic value, this fails to measure the intrinsic value of that species. In the same way, the maximum amount of money one person may be willing to pay to prevent the loss of another person's life fails to reflect the value of that life. Pearce (1998, p. 363) has stated that 'willingness to pay for non-use may well capture socalled "ethical" preferences'. In contrast, non-utilitarian and more generally non-consequentialist reasoning seem particularly relevant restrictions upon the applicability of environmental valuation. As Lockwood (1999) explains, an individual can simultaneously be prepared to trade some entities and regard others hierarchically while relating different conceptions of value to different entities (that is, intrinsic value, instrumental value and no value at all). There are multiple values which can be expressed in relation to the environment and no reasons why these should all be reducible to WTP. Environmental philosophers have attempted to raise awareness of the policy relevance of refusals to make trade-offs on ethical grounds (Holland 1995; O'Neill 1993). As Holland (1995, p. 22) notes: 'to be asked to trade one's principles, even hypothetically, is likely to seem inappropriate and even morally disreputable'.

Another way in which economic approaches are limited is with regard to life support functions and ecosystem functions. The functions which ecosystems perform are many and varied. Only a minority of these fall within the framework where they can be bought and sold in markets subject to private ownership. Among the most important functions performed by ecosystems are maintenance of climatic stability and nutrient cycles. Avoiding the loss of species habitats and sites of scientific interest will help maintain biodiversity. Biodiversity of ecosystems, genes and species is seen as an important aspect of nature and a key to sustainable economic systems.

CVM may be able to place monetary amounts on some aspects of species value or even ecosystem diversity but is unable to address many of the concerns raised by the need to maintain ecosystem functions and protect biodiversity. Where an identifiable output or service can be related to an ecosystem function and this output or service is connected to a marketed commodity, a production analysis approach may be able to assess the economic value of changes in ecosystem functions. However, environmental impacts can be complex, highly uncertain or unknown, such as the loss of a site-specific species which has never been classified. The general perception 
that biodiversity is equated to species is too simplistic and tends to ignore genetic and ecosystem diversity. However, the issue goes beyond merely a lack of information.

In the case where the functions are essential for life they then, by definition, have no substitutes and cannot be traded. Hierarchical and non-compensatory expressions such as lexicographic preferences are then logical expressions of value rather than exchange or trade values (Lockwood 1999). More generally, as Brown (1984) has noted, functional values are outside of typical preference structures in economics because there is little sense in regarding them as matters of consumer choice, for example, discussing a preference for having or destroying the ozone layer. This reasoning has led some, including a few who have rejected the notion of ethical refusals to trade, to accept that ecosystems have a set of values which are outside economic valuation, that is, they are primary or above other values (Gren et al. 1994). In addition, Common and Perrings (1992) have shown, using resource models, how efficiency in resource allocation is neither a necessary nor a sufficient condition for sustainability of resource use, and have noted the importance of ecosystem resilience. They emphasize that this implies an approach which 'privileges the requirements of the system above those of the individual' (p. 32) and that this involves ethical judgements. Common and Perrings then regard consumers as sovereign only as long as they avoid threatening the general system and so the welfare of future generations. Thus, the ethical categories of limitation on economic valuation and those from ecology become linked. Those regarding some ecosystem functions as having a primary or functional value are in fact implicitly attributing an intrinsic value to survival, that is, survival is then an end in itself regardless of reference to any other entity.

\section{CONCLUDING REMARKS}

Environmental valuation in economics has expanded dramatically since the 1980s due in part to the growing public policy concern over environmental management. The use of CBA for environmental assessment has become focused around the CVM because of its potential to address so many issues and provide a more inclusive value. At the same time, many questions have been raised as to the meaning and limitations of monetary valuation of the environment. The environmental economist in the neo-classical tradition prefers to avoid political and ethical questions and exclude these from the analysis, but this seems impossible given the beast with which we are grappling. Thus, the issues raised in this chapter, which are apparent in the work presented in this volume, show that the approach economists are and 
have been taking to environmental issues will need to change. Some aspects of that change should be to acknowledge explicitly the sensitivity of results, their context specificity and the limited category of values that economists generally address and supply to the policy process. This may then encourage more novel research and wider attention to alternative processes of expressing environmental values. If those values which cannot be captured in a monetary calculus are ignored, they will continue to be lost just as the environment has been and is being degraded, damaged and destroyed due to the neglect of pollution. The challenge is to recognize that pollution impacts on multiple and non-comparable values, and that we need to design institutional processes which allow for the expression of different discourses.

\section{REFERENCES}

Adams, J.G.U. (1995), Cost-benefit Analysis: Part of the Problem, Not the Solution, Oxford: Centre for Environmental Policy and Understanding, Green College.

Arrow, K., R. Solow, P.R. Portney, E. Leamer, R. Radner and H. Schuman (1993), Report of the NOAA Panel on Contingent Valuation, Washington, DC: Resources for the Future.

Bergstrom, J.C. and P. DeCivita (1999), 'Status of benefit-transfer in the United States and Canada: a review', Canadian Journal of Agricultural Economics, 47(1): 79-87.

Brouwer, R., N. Powe, K. Turner, I.J. Bateman and I.H. Langford (1999), 'Public attitudes to contingent valuation and public consultation', Environmental Values, 8(3): 325-47.

Brouwer, R. and F.A. Spanninks (1999), 'The validity of environmental benefits transfer: further empirical testing', Environmental and Resource Economics, 14(1): 95-117.

Brown, T.C. (1984), 'The concept of value in resource allocation', Land Economics, 60(3): 231-46.

Common, M. and C. Perrings (1992), 'Towards an ecological economics of sustainability', Ecological Economics, 6: 7-34.

Cummings, R.G., D.S. Brookshire and W.D. Schulze (1986), Valuing Environmental Goods: An Assessment of the Contingent Valuation Method, Totowa, NJ: Rowman \& Allanheld.

Department of the Environment, Transport and the Regions (1999), The Environmental Costs and Benefits of the Supply of Aggregates: Phase 2, London: Department of the Environment, Transport and the Regions.

Downing, M. and T. Ozuna (1996), 'Testing reliability of the benefit transfer approach', Journal of Environmental Economics and Management, 30(3): 316-22.

Foster, J. (ed.) (1997), Valuing Nature? Economics, Ethics and Environment, London: Routledge.

Gren, A.M., C. Folke, K. Turner and I. Bateman (1994), 'Primary and secondary values of wetland ecosystems', Environmental and Resource Economics, 4(1): 55-74.

Hanley, N. and C.L. Spash (1993), Cost-benefit Analysis and the Environment, Aldershot, UK: Edward Elgar.

Hausman, J.A. (ed.) (1993), Contingent Valuation: A Critical Assessment, Amsterdam: North-Holland. 
Helming, J.F.M. (1997), 'Impacts of manure policies for the Netherlands', in F. Brouwer and W. Kleinhanss (eds), The Implementation of Nitrate Policies in Europe: Processes of Change in Environmental Policy and Agriculture, Kiel: Wissenschaftsverlag Vauk, pp. 235-51.

Holland, A. (1995), 'The assumptions of cost-benefit analysis: a philosopher's view', in K.G. Willis and J.T. Corkindale (eds), Environmental Valuation: New Perspectives, Wallingford: CAB International, pp. 21-38.

Kirchhoff, S., B.G. Colby and J.T. LaFrance (1997), 'Evaluating the performance of benefit transfer: an empirical inquiry', Journal of Environmental Economics and Management, 33(1): 75-93.

Kleinhanss, W., H. Becker and K.-H. Schleef (1997), 'Impacts of agri-environmental policy measures on nitrogen emissions from agriculture', in E. Romstad, J. Simonsen and A. Vatn (eds), Controlling Mineral Emissions in European Agriculture: Economics, Policies and the Environment, Wallingford: CAB International, pp. 137-55.

Knetsch, J.L. (1994), 'Environmental valuation: some problems of wrong questions and misleading answers', Environmental Values, 3(4): 351-68.

Lockwood, M. (1999), 'Humans valuing nature: synthesising insights from philosophy, psychology and economics', Environmental Values, 8(3): 381-401.

Merrifield, J. (1997), 'Sensitivity analysis in benefit-cost analysis: a key to increased use and acceptance', Contemporary Economic Policy, 15(July): 82-92.

O'Neill, J. (1993), Ecology, Policy and Politics: Human Well-being and the Natural World, London: Routledge.

O'Neill, J. (1997), 'Managing without prices: on the monetary valuation of biodiversity', Ambio, 26: 546-50.

Pearce, D. (1998), 'Valuing risks', in P. Callow (ed.), Handbook of Environmental Risk Assessment and Management, Oxford: Blackwell Science, pp. 345-75.

Pearce, D.W., W.R. Cline, A.N. Achanta, S. Frankhauser, R.K. Pachauri, R.S.J. Tol and P. Vellinga (1996), 'The social costs of climate change: greenhouse damage and the benefits of control', in J.P. Bruce, H. Lee and E.F. Haites (eds), Climate Change 1995: Economic and Social Dimensions of Climate Change, Cambridge: Cambridge University Press, pp. 178-224.

Pearce, D.W., A. Markandya and E.B. Barbier (1989), Blueprint for a Green Economy, London: Earthscan.

Pearce, D.W. and R.K. Turner (1990), Economics of Natural Resources and the Environment, New York: Harvester Wheatsheaf.

Radford, A.F., A.C. Hatcher and D.J. Whitmarsh (1991), An Economic Evaluation of Salmon Fisheries in Great Britain: Summary Report, Portsmouth: Centre for Marine Resource Economics, Portsmouth Polytechnic.

Sagoff, M. (1988), The Economy of the Earth: Philosophy, Law, and the Environment, Cambridge: Cambridge University Press.

Schleef, K.-H. (1996), Impacts of Policy Measures to Reduce Nitrogen Surpluses from Agricultural Production: An Assessment at Farm Level for the Former Federal Republic of Germany, Braunschweig, Bundesforschungsanstalt für Landwirtschaft, Institut für Betriebswirtschaft, Arbeitsbericht.

Spash, C.L. (1997), 'Environmental management without environmental valuation?', in J. Foster (ed.), Valuing Nature? Economics, Ethics and Environment, London: Routledge, pp. 170-85.

Spash, C.L. (1998), 'Investigating individual motives for environmental action: lexicographic preferences, beliefs and attitudes', in J. Lemons, L. Westra and 
R. Goodland (eds), Ecological Sustainability and Integrity: Concepts and Approaches, Dordrecht, The Netherlands: Kluwer Academic Publishers, vol. 13, pp. 46-62.

Spash, C.L. (2000), 'Ecosystems, contingent valuation and ethics: the case of wetlands re-creation', Ecological Economics, 34(2): 195-215.

Spash, C.L. and N. Hanley (1995), 'Preferences, information and biodiversity preservation', Ecological Economics, 12(3): 191-208.

Vatn, A. and D.W. Bromley (1994), 'Choices without prices without apologies', Journal of Environmental Economics and Management, 26(2): 129-48.

Willis, K. (1995), 'Contingent valuation in a policy context: the National Oceanic and Atmospheric Administration Report and its implications for the use of contingent valuation methods in policy analysis in Britain', in K.G. Willis and J.T. Corkindale (eds), Environmental Valuation: New Perspectives, Wallingford: CAB International, pp. 118-43. 